\title{
Mobility Perspective in Anthropology of Policy: Case Studies Urban Policy in Indonesia
}

\section{Perspektif Mobilitas dalam Antropologi Kebijakan: Studi Kasus Kebijakan Kota di Indonesia}

\author{
Haryo Kunto Wibisono', Semiarto Aji Purwanto² \\ 1Universitas Indonesia, Indonesia. Email: haryo.kunto@ui.ac.id \\ ${ }^{2}$ Universitas Indonesia, Indonesia. Email: semiarto.aji09@ui.ac.id
}

\begin{tabular}{|c|c|}
\hline ARTICLE INFO & ABSTRACT \\
\hline $\begin{array}{l}\text { Keywords: } \\
\text { Anthropology of policy; } \\
\text { Balikpapan; creative city; } \\
\text { policy mobility; Indonesia. }\end{array}$ & $\begin{array}{l}\text { This article explores anthropological perspectives in public policy by } \\
\text { using the central concept of policy mobility. This concept will show } \\
\text { how policy resulting from the accumulation of knowledge, strength, } \\
\text { and geographical imagination moves from one territory to another. } \\
\text { The emphasis on forming policy ideas is different from policy studies } \\
\text { from another perspective that looks at governance to shape people's }\end{array}$ \\
\hline How to cite: & behavior. We take the case of forming creative city ideas in \\
\hline Wibisono, H.K., & Balikpapan, East Kalimantan to show mutation and hybridization of \\
\hline Purwanto, S.A., (2020). & policies. We use ethnographic methods to collect data, supplemented \\
\hline Mobility Perspective in & by literature reviews on creative city policies. For decades, \\
\hline Anthropology of Policy: & $\begin{array}{l}\text { Balikpapan has been known as an extractive industrial city, } \\
\text { especially in the mining and forestry sectors. Due to pressure from }\end{array}$ \\
\hline $\begin{array}{l}\text { in Indonesia. ETNOSIA: } \\
\text { Iurnal Etnografi }\end{array}$ & $\begin{array}{l}\text { national and global environmentalists, exploration of natural } \\
\text { resources must be limited, reducing urban productivity. }\end{array}$ \\
\hline Indonesia. 5(2): $265-283$ & $\begin{array}{l}\text { Policymakers see the creative city as an opportunity to improve the } \\
\text { city's economic life while maintaining the sustainability of the local }\end{array}$ \\
\hline DOI: & natural and cultural environment. \\
\hline 10.31947/etnosia.v5i2.11682 & \\
\hline
\end{tabular}

\section{Pendahuluan}

Sebagai sebuah bidang kajian, antropologi kebijakan amat dipengaruhi oleh tulisan Shore \& Wright (2003). Mereka menjelaskan kebijakan sebagai teks kultural, alat klasifikasi, narasi yang dipakai untuk menjustifikasi atau mengkritik kondisi sekarang, atau alat retorika dan formasi diskursif yang berfungsi untuk menguatkan satu pihak atau malah mengeksklusi pihak lain. Keduanya berkeinginan membuka kemungkinan baru yang lebih luas dari kepengaturan, kuasa, dan perubahan sosial yang membentuk kehidupan sosial hari ini. Kebijakan pada dasarnya melekat dalam kehidupan sosial dan kultural serta "process of being", serta tidak melulu berkaitan dengan kuasa, teks, 
eksternal, dan tergeneralisir melainkan berlangsung secara produktif, performatif, dan selalu berada dalam kontestasi.

Melalui analisis proses kebijakan, fragmentasi budaya, dibawa secara bersamaan untuk masuk ke dalam semantik sosial baru. Dalam operasionalisasi kebijakan (work of policy) berlaku pula kegiatan mengklasifikasi dan mengorganisasi orang dan gagasan ke dalam cara yang baru, sehingga bisa dipahami bahwa kebijakan adalah wahana yang sangat berkuasa untuk melakukan perubahan sosial. Kebijakan bisa menyediakan instrumen untuk mengkonsolidasikan legitimasi dari tertib sosial yang sudah ada atau menyediakan rasionalisasi dari perubahan rejim, atau pergeseran atas tertib sosial yang sudah mapan (Shore et al., 2011, p. 3).

Pendekatan yang ditawarkan oleh Shore dan Wright $(2003,2011)$ ini memicu perspektif governmentality yang menggarisbawahi kebijakan sebagai cara untuk membentuk perilaku manusia, proses subjektivikasi atau pembentukan subjek, dan praktik diskursif. Mereka mencoba untuk lepas dari kerangka analisa kebijakan yang berpijak pada kacamata rasional-instrumentalistik yang mana banyak disumbang oleh disiplin ilmu pemerintahan, politik atau administrasi publik. Persoalannya, pendekatan ini mengecilkan praktik mobilitas ide (Urry, 2000) dan mobilitas teknologi (Ong, 2007) yang berpendapat bahwa praktik kekuasaan memiliki mobilitas untuk berpindah tempat; di sisi lain, praktik kebijakan tertentu adalah hasil dari transfer, mimikri dan mutasi yang pernah beroperasi dari satu negara tertentu. Proses ini oleh Peck \& Theodore (2010) dan Mc Cann (2011) disebut mobilitas kebijakan (policy mobility). Teknologi kekuasaan pada konteks ini terkait dengan praktik diskursif, norma, serta kerangka pembentukan subjektivikasi.

Melalui artikel ini kami bermaksud memperluas kajian antropologi dalam memahami kebijakan publik dengan lebih memperhatikan mobilitas kebijakan. Dengan cara ini kami melihat potensi menemukan bagaimana kebijakan berupa program pembangunan, misalnya, memiliki dampak sosial ekonomi atau politik terhadap masyarakat. Studi kritis terhadap pembangunan lazimnya mengamati proses integrasi masyarakat lokal ke ekonomi global, transformasi kehidupan sehari-hari warga lokal, isu marginalisasi kelompok masyarakat tertentu berikut ketimpangan yang dihasilkannya (Li, 2007, 2014; Lowe, 2003; Robinson, 1986; Tsing, 1993). Studi kasus yang kami tampilkan di kota Balikpapan akan berfokus pada introduksi industri kreatif di kota itu.

Industri kreatif, lebih khusus lagi kota kreatif menjadi studi kasus yang menarik untuk memahami bagaimana proses mobilitas ide, pengetahuan, eksemplar dan praktik kebijakan yang dibentuk secara global dan melintasi banyak negara, serta bagaimana proses mutasi dan hibridisasi pengetahuan sekaligus kebijakan dipraktikkan suatu negara (Aritenang, 2015; Prince, 2010, 2014; Rossi, 2017). Berbagai kajian di bidang ini juga mengkritisi model perencanaan urban yang bertujuan menempatkan kota pada skala global (González, 2006; Roy \& Ong, 2011; Bunnell et al., 2013; Bunnell, 2015; Söderström, 2014). Melalui kota kreatif, hampir semua kota di seluruh dunia, menginginkan dirinya untuk menjadi kota kelas dunia, menyediakan situasi dan 
kondisi sebaik-baiknya agar warganya menjadi wiraswasta, menyediakan orientasi ulang ekonomi perkotaan, dan mengembalikan lagi rasa kepemilikan warga terhadap kotanya.

Artikel ini berisi telaah konseptual dan refleksi teoritik dalam rangka memahami kebijakan kota kreatif. Melalui perspektif mobilitas kebijakan pada konteks kebijakan kota kreatif, kami ingin mengulas bagaimana proses transnasionalisasi, mutasi dan hibridisasi sebuah kebijakan yang ditempuh kota untuk menjadi kelas kota dunia, menyediakan situasi dan kondisi sebaik-baiknya agar warganya menjadi wiraswasta, menyediakan orientasi ulang ekonomi perkotaan, dan mengembalikan rasa kepemilikan warga terhadap kotanya.

\section{Metode}

Dalam studi ini kami tidak sekedar melihat kebijakan kota kreatif belaka namun mengembangkan cara baru dalam memahami kebijakan dengan fokus pada genealogi ide, proses mobilitas ide yang dibawa oleh aktor kebijakan dari level internasional hingga ditranslasi ke tingkat lokal, rasionalisasi kebijakan, target intervensi kebijakan, serta tipe kebijakan yang dihasilkan hingga implikasinya pada elemen kota yang terdampak. Secara khusus, kami juga melihat jenis subjek baru dan relasi kuasa yang dihasilkan dari satu jenis kebijakan.

Kami mengandalkan dokumen kebijakan seperti Musrenbang (Musyawarah Perencanaan Pembangunan Daerah), RKPD (Rencana Kerja Pembangunan Daerah), RPJMD (Rencana Pembangunan Jangka Menengah Daerah), Rencana Aksi Jangka Menengah 2015-2019 Ekonomi Kreatif dari Badan Ekonomi Kreatif Pusat sebagai sumber kajian dokumen. Kami menafsirkan dokumen tersebut melalui cross check kepada pembuat kebijakan tingkat pusat yaitu Bekraf pusat dan komunitas kreatif tingkat daerah serta melihat implementasinya untuk menemukan memperlihatkan bagaimana narasi, produksi pengetahuan, sistem pengklasifikasian sektor, dan problematisasi konteks. Meletakkan dokumen dalam kajian etnografis pada dasarnya mencoba menafsir alat klasifikasi, retorika, formasi diskursif yang menjustifikasi keadaan sekarang dan mengkritisi masa lampau (Shore \& Wright, 2003, pp. 11-12)

Data empiris diperoleh melalui studi etnografi kebijakan di Kota Balikpapan, Kalimantan Timur sepanjang 2016-2018. Data kami ambil dari observasi beberapa event penting seperti hari ulang tahun kota, Seminar Developer Day, diskusi informal yang bertajuk Kerja dan Keindahan, untuk kemudian dilanjutkan dengan wawancara ke komunitas kreatif daerah lalu kami bandingkan dengan keterangan wawancara dengan para pejabat Badan Ekonomi Kreatif (Bekraf) Pusat. Balikpapan kami pilih sebab semenjak krisis batubara tahun 2014-2016, kota ini mengadopsi ekonomi kreatf sebagai orientasi ekonomi perkotaan. Selanjutnya, upaya tersebut menambah identitas yang semula dikenal sebagai Kota Minyak menjadi Kota Kreatif dan Kota yang Nyaman. 


\section{Hasil dan Pembahasan}

\section{Kebijakan dalam perspektif mobilitas}

Dalam kajian ilmu sosial, penggunaan mobilitas sebagai kerangka analisis banyak dipengaruhi oleh tulisan Urry (2000) yang melihat bahwa aspek mobilitas dari orang, objek, citra, dan informasi travel akan memproduksi dan mereproduksi bentuk kultural dan kehidupan sosial. Ia mencatat, secara umum, ada empat elemen terkait dalam mobilitas yang menghasilkan praktik sosial tertentu, yaitu (1) corporeal travel, dari orang yang bekerja, berjalan bermigrasi atau kegiatan apapun yang mengkontraskan modalitas ruang-waktu, (2) mobilitas objek, dari objek ke produser, pelanggan dan retail, menuju penerima dan pengirim hadiah atau souvenir, atau objek dan ruang, 3) imaginative mobilites yang dihadirkan atau dimediasi oleh perangkat komunikasi, semisal televisi, radio, dan sosial media, 4) virtual travel berupa kehadiran orang yang berjarak secara geografis, yang mengkorespondensi sensasi seseorang untuk seolah-olah hadir dalam ruang dan waktu yang berbeda, misalnya dalam cyberspace.

Ide ini kemudian dipertajam dengan istilah perspektif mobilitas atau mobility turn (Sheller \& Urry, 2006; Faist, 2013;) yang memperjelas mobilitas sebagai kerangka pikir yang meyakini sebuah proses gerakan citra dan informasi dari lokal, nasional, dan media global. Konsep ini memperlihatkan bagaimana komunikasi masa kini menimbulkan efek berjejaring dan melekatnya hubungan melalui teknologi internet dan komputer. Konsep mobilitas juga dikembangkan ahli geografi manusia yang mengasumsikan kebijakan sebagai praktik yang mobile dari satu tempat ke tempat lain (Mccann, 2011; Peck, 2011; Peck \& Theodore, 2010). Kebijakan, bukan sesuatu yang bersifat lokal meskipun hasil rakitan (assemblages), yaitu produk dari para ahli, praktik, contoh, dan model yang ada pada satu lokasi dan waktu tertentu. Pendekatan mobilitas kebijakan mempersoalkan karakter mengglobalnya sebuah kota, berfokus pada model kebijakan partikular bersirkulasi dalam beragam lokasi, menganalisis praktik dan politik yang berkembang dalam dimensi global-lokal, dan mengandung komunitas epistemik yang mentransfer, menempatkan dan mendayaagunakan pengetahuan tertentu sebagai bagian dari praktik kebijakan (Jonas et al., 2015; Mccann, 2011; McCann \& Ward, 2012; Peck \& Theodore, 2010; Temenos \& Mccann, 2013). Artinya, pendekatan ini melihat karakter pengetahuan, keahlian, dan rasionalitas kepengaturan dalam menciptakan hegemoni; dan bagaimana para aktor, praktik, representasi, dan diskursus membentuk pengetahuan dan kebenaran.

Berbeda dengan ahli antropologi lain yang mengkaji kebijakan, khususnya internasionalisasi kebijakan dengan memperlihatkan bagaimana penataan secara spesifik antara aktor dan kelembagaan dalam membentuk kebijakan (Shore dan Wright, (2011;2003) para ahli geografi memahami bagaimana aktor kebijakan saling berinteraksi, beraliansi atau berkontestasi dalam sirkuit pengetahuan kebijakan. Selanjutnya objek analisis mereka arahkan pada siapa yang membuat dan memobilisasi kebijakan yang bersangkutan (Baker et al., 2016, pp. 220-221). Pendekatan mobilitas kebijakan bagi Jamie Peck (2011) sangat berbeda dengan 
perspektif kebijakan yang berpijak pada rational-choice dan esensialis, atau formalist representations dari transfer kebijakan yang biasa dipakai oleh ilmu politik. Pendekatan ini ada di dalam pandangan social-constructivist dengan memperhatikan mutasi serta peran dari konteks spasio-temporal yang banyak digunakan oleh ahli antropologi, geografi, sosiologi, dan perencanaan kota.

Peck (2011) menjelaskan perlunya memperhatikan situasi dan kondisi makrokelembagaan, suatu relasi yang memungkinkan terjadinya mobilitas. Tentu, sebelumnya harus melihat proses transfer dari inovasi yang akhirnya mengilhami sebuah kebijakan. Kebijakan selalu berkontestasi pada satu kategori spasial tertentu; perbedaan konjungtur antara geografi-historik, bentuk sosial dari mobilitas kebijakan, dan ontologi kebijakan akan diukur dan masuk dalam problem kebijakan.

Jika proses mobilisasi bersifat global dan lintas-teritori, maka kebijakan akan mewujud dalam eksperimen dan model yang dikonstruksi sesuai kondisi lokal. Demikian pula dengan aliran pengetahuan, keahlian, teknologi, dan aktor kebijakan yang mengkoneksikan dan membuat kembali situs lokal dari pembuatan kebijakan. Dalam konteks perkotaan, kebijakan menghasilkan imajinasi spasial yang terhubung dengan kesuksesan pembangunan urban dan regenerasi lanskap perkotaan yang diadopsi oleh para elite, serta menjadi perantara antara aktor nasional serta supranasional (Brenner et al., 2010). Perspektif ini memperlihatkan proses hibridisasi, transmutasi, dan variasi dari sirkulasi logika kelembagaan global serta proses adaptasi ke dalam berbagai setting kelembagaan, kondisi politik-ekonomi, dan struktur ideologi-politik.

Memahami mobilitas kebijakan bukan berarti melihat konstelasi global dalam ruang horisontal, namun lebih kepada vertikal yang ditafsirkan dalam pembagian wilayah geografi politik global seperti Negara Eropa-Atlantik Utara, Asia-Afrika-Amerika Latin, Negara Dunia Pertama, Dunia Kedua hingga Dunia Ketiga, atau Negara PusatNegara Pinggiran. Pembagian geografi ini menentukan bagaimana proses mobilitas kebijakan dijalankan serta berimpitan dengan relasi kuasa dan sejarah kolonialisasi yang bisa menjadi justifikasi bagi diterapkannya kebijakan tertentu. Beberapa contoh kesuksesan pembangunan urban yang terjadi di negara Eropa dan Amerika Serikat menjadi inspirasi bagi aparatur pemerintahan untuk melihat ceruk baru dalam ekonomi perkotaan. Mc Cann (2011) menjelaskan sekalipun mengandung kekurangan akibat kecenderungan Eropasentris dan melihat kolonialisme sebagai elemen penting perspektif mobilitas kebijakan tetap relevan.

\section{Kebijakan Kota Kreatif di Indonesia}

Pada bagian ini, kami memfokuskan perhatian bagaimana kebijakan pembaruan urban di Indonesia yang banyak direpresentasikan lewat lingua franca baru perkotaan yaitu kota kreatif. Kami berpendapat bahwa kota kreatif adalah salah satu contoh policy mobility sebab dibentuk oleh berbagai lembaga internasional mulai dari British Council, UNESCO (United Nations Educational, Scientific and Cultural Organization), UNDP (United Nations Development Programme), serta kebijakan ini bergerak dari satu negara ke negara lain, dari daerah satu ke daerah lain. Kebijakan ini-dinarasikan dan 
diperbincangkan dalam ruang seminar, konferensi, talkshow, perumusan kebijakan para aparatur negara, hingga ke sosial media. Berbagai kisah sukses dibawa oleh aparatur negara hingga warga kota untuk kemudian menjadi legitimasi atas berlakunya kebijakan ini di wilayahnya masing-masing. Sebagai contoh, Ridwan Kamil yang pada saat menjabat Walikota Bandung pernah menjadi pembicara dalam TedX Jakarta, tahun 2010, dengan tajuk Creativity and Design for Social Change in Cities. Ia menjelaskan kreativitas dan sumber daya manusia sebagai upaya penyelamatan kota. Ridwan Kamil dalam presentasinya menyatakan komunitas kreatif, jejaring kolaborasi antar kota dan antar warga sebagai sendi utama perkembangan kota masa kini. Komunitas inilah yang menjadi penggerak dalam menyelesaikan berbagai masalah perkotaan, mulai kemiskinan hingga keindahan kota.

Secara normatif, beberapa aktor yang terlibat dalam kebijakan ini sepakat untuk menekankan pentingnya kreativitas sebagai basis dalam pembangunan urban. Sebagaimana pernyataan UNESCO yang mencanangkan jejaring kota kreatif dalam nama UNESCO Creative City Network di tahun 2004 dengan statement sebagai berikut,

".. the UNESCO Creative Cities Network (UCCN) aims to strengthen cooperation with and among cities that have recognized creativity as a strategic factor of sustainable development as regards economic, social, cultural and environmental aspects. By joining the Network, cities acknowledge their commitment to sharing best practices, developing partnerships that promote creativity and the cultural industries, strengthening participation in cultural life and integrating culture in urban development plans. The Network further commits to supporting the United Nations frameworks, particularly the 2030 Agenda for Sustainable Development. The UNESCO Creative Cities Network covers seven creative fields: Crafts and Folk Art, Design, Film, Gastronomy, Literature, Media Arts, and Music." (Unesco Creative City Network, Mission Statement)

Pada dasarnya kebijakan ini juga hasil upaya aktif kota-kota di Indonesia menyamai pencapaian kemajuan beberapa negara Eropa seperti Inggris yang sukses mengenalkan negaranya lewat seni dan budaya. Inggris pula yang membuat kata kreatif dibakukan sebagai kerangka kebijakan lewat DCMS (Department of Communication, Media and Sport) untuk kemudian ditelurkan dalam rencana aksi sebagaimana yang kami sampaikan di tabel 1. Sementara itu, dari kawasan Asia, keberhasilan Jepang dan Korea Selatan yang mengenalkan Hallyu dan Manga menjadi inspirasi bagi beberapa negara di Asia Tenggara untuk mengikuti jejak dua saudaranya dari Asia tersebut. Kami akan mengawali bahasan dalam sub-bagian ini dengan memperlihatkan asal muasal gagasan kota kreatif hingga masuk ke Indonesia dan kemudian ditranslasikan pada kota seperti Kota Balikpapan.

\section{Genealogi Gagasan Kota Kreatif}

Gagasan kota kreatif ditopang oleh dua pemikir utama yaitu Landry (2000) dan Florida (2003). Keduanya memiliki latar belakang ilmu perencanaan kota. Landry berangkat pemahaman bahwa manusia adalah salah satu sumber daya yang sangat potensial dalam kota. Sumber daya ini terdiri dari kecerdasan manusia, hasrat, imajinasi, dan kreativitas. Ini akan menjawab problem kota hari ini berupa masalah kreativitas dan inovasi. Kota kreatif menurutnya adalah perkara membuat "kota yang baik" dengan 
menargetkan orang sebagai aset utama yang mencakup talenta, skill dan kreativitas. Urban planner harus mampu menjadikan kota bernafaskan imajinasi manusia, kompetensi dan kapabilitas manusia untuk berkompetisi. Ia mencontohkan banyak sumber daya di kota yang dilupakan selama ini antara lain bahasa, makanan, waktu luang, pakaian dan subkultur, atau tradisi intelektual. Sumber daya budaya dinilai sebagai bahan mentah dari kota dan bernilai serta akan menggantikan aset tradisional. Kreativitas adalah cara untuk mengeksploitasi sumber daya ini dan membuatnya berkembang, sehingga tugas utama perencana kota adalah mengakui, mengatur, dan membantu mereka tumbuh kembang. Kota kreatif dengan demikian adalah solusi dalam melihat problem perkotaan seperti keamanan, kesenjangan antara mereka yang berupah tinggi dan berupah rendah, ketidakpuasan dalam lingkungan fisik, dan kekhawatiran akan hilangnya lokalitas, terutama keterikatan pada tempat (bersejarah) dan identitas.

Gagasan kedua dari Florida (2003) yang membayangkan kota yang berfungsi untuk menarik kelompok dari kelas kreatif, mengaktivasi human kapital demi perkembangan regional, pencapaian kembali identitas kota yang hilang dan penciptaan ruang kota yang masyhur disebut ruang kreatif. Ide ini ditujukan atas nama kota yang ramah yang berbasis pada talenta, toleransi dan teknologi. Kota kreatif dalam pembacaan Florida dengan cepat akan memobilisasi talenta, sumber daya, dan kapabilitas yang dibutuhkan untuk merubah inovasi menjadi ide bisnis dan produk komersial sekaligus kemampuan mendayagunakan human kapital atau talenta menciptakan keuntungan regional. Kreativitas berbentuk modal kreatif ini bisa dihasilkan oleh kelas kreatif, yang terdiri super-creative core antara lain, ilmuwan, insinyur, artis, dan arsitek yang merupakan leadership thought dalam masyarakat. Berikutnya adalah profesional kreatif yang tediri dari pekerjaan knowledge-based di sektor hi-tech, layanan finansial, dan manajemen. Kelas kreatif harus ditarik-masuk dalam kota kreatif yang mengusung teknologi, talenta, dan toleransi dan disatukan dalam satu tempat yaitu creative center.

Kedua pemikiran di atas berujung pada gagasan ekonomi kreatif, yang menurut Healy (Healy, 2002, p. 91) muncul dalam dua versi. Pertama, mereka yang sepakat sektor kreatif sebagai bagian dari ekonomi baru yang bertumbuh sangat cepat; dan ke dua, para ahli yang melihat sektor kreatif sebagai wahana yang memunculkan pekerja kreatif. Pekerja kreatif adalah bagian paling esensial dari vitalitas kota. Gagasan ini semakin menyebar terutama pada bidang kebijakan budaya, yang berorientasi pada penguatan budaya lokal yang memiliki nilai ekonomi, sehingga sektor budaya menjadi sepadan dengan kebijakan ekonomi dengan isu pertumbuhan, produktivitas, dan kompetitif. Lebih jauh, Healy (2002) mencatat titik temu dari dua argumen John Howkins dan Richard Florida yaitu ekonomi baru berdasar informasi, teknologi, pengetahuan dan inovasi sekaligus membentuk subjek yang fleksibel dan berjejaring. Ekonomi ini dipandu oleh komoditi yang didesain secara baik, barang dan jasa yang dipasarkan serta dilindungi hak kekayaan intelektualnya.

Menyatunya budaya dan ekonomi ini di kemudian hari diadaptasi oleh Department of Culture, Media and Sport (DCMS) Inggris merancang Creative Industries Mapping 
(Council, 2010) sebagai cara untuk mengukur dan mendefinisikan industri kreatif di tengah lanskap ekonomi Britania yang sedang berubah. DCMS juga memuat apa saja intervensi kebijakan yang dilakukan dalam rangka menopang industri kreatif dan salah satunya menyasar kebijakan budaya dan problem pembangunan lokal, seperti tabel 2 di bawah ini. Kata kunci dalam pengklasifikasian industri kreatif dalam dokumen ini dipandu pada pengertian pada kegiatan yang berasal dari kreativitas individual, skill dan talenta yang memiliki potensi untuk mendatangkan kemakmuran dan penciptaan lapangan kerja melalui pemanfaatan kekayaan intelektual.

Tabel 2. Wilayah Kajian Kebijakan Industri Kreatif

\begin{tabular}{|c|c|c|}
\hline Kebijakan lokal & $\begin{array}{c}\text { Kebijakan industrial } \\
\text { nasional }\end{array}$ & Kebijakan budaya \\
\hline $\begin{array}{ll}\text { - } & \text { Kota atau pertumbuhan } \\
& \text { regional } \\
\text { - } & \text { Regenerasi } \\
\text { - } & \text { Pembangunan kluster } \\
\text { lokal dan regional } \\
\text { - } & \begin{array}{l}\text { Diversifikasi ekonomi } \\
\text { regional }\end{array} \\
\text { - } & \text { Place-making/city dan } \\
\text { regional branding }\end{array}$ & $\begin{array}{ll}\text { - } & \text { Inovasi } \\
\text { - Kompetitif secara } \\
\text { internasional }\end{array}$ & $\begin{array}{ll}\text { - } & \text { Arsitektur } \\
\text { - } & \text { Kerjasama budaya } \\
\text { - } & \text { Diversitas kultural } \\
\text { - } & \text { Identitas kultural } \\
\text { - } & \text { Bentuk baru budaya }\end{array}$ \\
\hline
\end{tabular}

Sumber: Mapping The Creative Industries: A Toolkit. DCMS (2010, 30)

Di beberapa negara lain, kota kreatif dianggap memicu kesadaran cara berkota yang baru seperti di Shanghai (O'Connor \& Gu, 2015); alternatif transisi ekonomi dari Jerman Timur ke Jerman Bersatu (Lange, 2015); atau perubahan citra kota yang dulunya identik dengan warna maskulin industrial seperti biru ke warna yang lebih feminin yaitu pink (Van den Berg, 2012). Di berbagai kota seperti Vancouver, Guangzhou, dan Shanghai mulai muncul upaya untuk memenuhi sisi potensi kreatif dari kota yang bersangkutan, seperti kreatif urbanisme yang berputar di sekitar ekonomi baru, (ekonomi kultural, teknologi tinggi), ekstraksi kapabilitas human kapital, kebijakan budaya dan istilah inovatif dari desain urban dan arsitektur (Scott, 2014). Selain itu muncul pusat produksi budaya yang baru seperti Seoul sebagai kota digital dan Nollywood di Nigeria (Cunningham, 2012)

\section{Para Mobilisator Gagasan Kota Kreatif}

Di Indonesia, program kota kreatif muncul saat pembentukan Badan Ekonomi Kreatif (Bekraf) tahun 2015, yang merupakan evolusi dari Kementerian Perdagangan dan Kementerian Pariwisata. Ekonomi kreatif di Indonesia ditandai dengan pergeseran orientasi kebudayaan yang tidak sekedar menuju pembangunan bangsa atau alat persatuan nasional namun penciptaan lapangancun pekerjaan dan pendapatan dari kebudayaan, melalui pariwisata serta penciptaan model industri kreatif (Jones, 2015). Model klasifikasi yang dianut oleh Bekraf meliputi aplikasi dan pengembangan, seni pertunjukan, periklanan, arsitektur, seni, kerajinan, desain, fashion, film, musik, , televisi dan radio, seni rupa, penerbitan, periklanan, musik, kuliner, kriya, fotografi, 
film, animasi dan video, desain komunikasi visual, fashion, desain produk, desain interior, arsitektur.

Keinginan untuk mengadopsi kebijakan kota kreatif juga dikondisikan dengan arus desentralisasi dan otonomi daerah yang memungkinkan terjadinya penonjolan sosok walikota atau kepala daerah inspiratif yang menuai pujian atas kesuksesan dalam pembangunan daerah. Berkat desentralisasi pula maka dimungkinkannya hubungan antar kabupaten dan hubungan antara kota dan kabupaten dalam memaksimalkan pendapatan asli daerah (Bunnell et al., 2013).

Sejak UNESCO memasukkan Kota Pekalongan -yang dikenal sebagai Kota Batiksebagai daftar Kota Kreatif dengan spesifikasi Craft and Folk Arts di tahun 2014, maka muncul keinginan dari beberapa kota di Indonesia untuk mengikuti jejak kota Pekalongan. Sebagaimana dalam laman UNESCO Creative City Network yang memasukkan Kota Bandung sebagai kota kreatif di tahun 2015, dengan spesifikasi Cities of Design yang menekankan produk fashion, design grafis, media digital.

Khusus Kota Bandung, kami mengamati Walikota Ridwan Kamil memegang peranan penting dalam mempromosikan Bandung sebagai destinasi wisata dan kota yang nyaman. Dalam rangka mencitrakan dirinya sebagai orang yang kreatif, Ridwan Kamil tidak lagi mengidentifikasi dirinya sebagai birokrat yang kaku atau politisi yang dianggap hanya mementingkan kelompok politik atau persoalan elektabilitas dalam pemilu, namun merangkul budaya populer yang dekat dengan 'kaum millenial' atau 'generasi Z'. Ia terlibat dalam pembuatan film populer Dilan 1991 dan Yo Wis Ben; dan aktif di sosial media, sehingga jarak antara aparatur negara dan warga semakin diperdekat. Artinya, untuk mengoperasikan gagasan kota kreatif dilihat pula dari keberadaan aparatus kota yang kreatif pula, dan ini bisa terlihat dari beberapa kebijakan publik yang mengkondisikan lahirnya talenta muda berbakat di kotanya masing-masing.

Hal menarik yang kami lihat dari kebijakan kota kreatif di Indonesia adalah bagaimana mobilisasi imajinari geografis dari apa yang disebut kota kreatif dengan menampilkan keberhasilan Korea Selatan dengan Hallyu, Jepang dengan manga, Inggris dengan Cool Britania, dan kemajuan Sillicon Valley yang melahirkan para pelopor industri hi-tech seperti Mark Zuckerberg, Steve Jobs, dan Elon Musk. Kisah keberhasilan ini banyak diinisiasi oleh para selebriti industri kreatif yang bertebaran di media sosial. Seorang perwakilan Deputi Bekraf pernah menuturkan kepada kami sebagai berikut,

"Ekonomi kreatif adalah bagian dari perkembangan zaman sebagaimana evolusi industri. berkembangnya teknologi digital, artifisial intelijen, dan tentunya kreativitas manusia sebagai penopang utama perekonomian di masa mendatang. Kreativitas manusia ini akan menyumbang pendapatan nasional sebab kreativitas manusia tidak akan habis dibandingkan dengan sumber daya alam. Karya anak negeri adalah inti utama ekonomi kreatif. Ada banyak potensi yang belum tergali dari warga Indonesia, misalnya ragam kopi nusantara yang sudah mendunia, sehingga pemerintah berkewajiban untuk memfasilitasi dan menstimulus potensi 
tersebut. Misalnya begini KFC (Kentucky Fried Chicken), yang mana produknya berasal dari Indonesia, namun lisensi dan merknya dari Amerika"

Berdasarkan buku Ekonomi Kreatif: Kekuatan Baru Indonesia Menuju 2025 (terbitan Bekraf tahun 2014), yang menjadi orientasi pembanguan ekonomi kreatif Indonesia, terdapat empat prinsip utama yang menjadi landasan utama dalam pengembangan ekonomi kreatif: (1) penguasaan ilmu pengetahuan dan teknologi yang merupakan hal vital dalam pengembangan ekonomi, (2) design thinking, berdasarkan kolaborasi ilmu dan kreativitas dengan menambahkan nilai-nilai termasuk nilai identitas budaya sebagai nilai tambah, (3) seni dan budaya sebagai inspirasi dalam berkarya, dan (4) media sebagai saluran distribusi dan presentasi karya dan konten kreatif.

\section{Imajinari Geografis dan kedatangan kebijakan Kota Kreatif}

Kota-kota yang mengapropriasi diskursus kreatif memiliki satu kesamaan dalam memahami apa yang ideal bagi warganya yaitu menjadikan warga wirausaha (entrepeneurial citizenship). Kelompok warga yang menjadikan resiko sebagai bagian keseharian, memiliki tingkat melek teknologi yang mumpuni, dan bisa menyelesaikan problem sosial perkotaan yang luput diselesaikan oleh aparatur kota seperti transportasi, kebersihan kota dan masih banyak lagi. Upaya ini mengadopsi kultur kerja millenial yang senang berpindah tempat kerja dan suasana kerja kasual. Kultur semacam ini hanya bisa diwujudkan jika aparatur kota merengkuh ide-ide anak muda, memperbarui kawasan urban untuk menyediakan tumbuh kembangnya talenta baru, memfasilitasi ekosistem industri kreatif yang diharapkan bisa menarik para investor untuk terlibat dalam pengembangan sektor industri kreatif..

Aparatur kota bergerak menjadi agensi dari transfer gagasan kota kreatif. Beberapa kota seperti Bandung, Yogyakarta, Denpasar dan Jakarta, berlomba menampilkan sisi atraktifnya dengan menampilkan keragaman budaya yang unik serta menjanjikan kenyamanan berhuni dan berkunjung dalam ide masyarakat multikultural. Salah satu upaya dalam menampikan keunikan ini adalah projek city branding. Kami ambil contoh Badan Perencanaan Pembangunan Daerah Kota Denpasar yang merilis buku Membangun Denpasar melalui City Branding (2010). Dalam buku tersebut terlihat Kota Denpasar mempromosikan logo kota yang baru dengan berakar pada tradisi budaya yaitu garis lengkung yang membentuk orang sedang menari Tarian Baris di tengah tulisan DEN dan PASAR. Logo ini diikuti pula dengan tagline Heart of Bali, sebagai penegasan Denpasar sebagai pusat pemerintahan, ekonomi, pariwisata, seni dan budaya.

Sementara bagi beberapa kota yang sebelumnya berbasis sumber daya alam seperti Kota Balikpapan di Kalimantan Timur, kami berasumsi bahwa ide kota kreatif dicanangkan dengan beberapa rasionalisasi berbeda. Pertama, menjadi dasar legitimasi orientasi ekonomi baru yang berjangkar pada pengembangan sumber daya manusia sebagai jawaban atas banyaknya restriksi pengelolaan sumber daya alam dari lembaga NGO internasional dan krisis pertambangan di tahun 2015. Ke dua, sebagai cara untuk merekatkan kembali rasa memiliki kota kepada warga setelah diwarnai ketidakpastian 
ekonomi. Ke tiga, mengembalikan lagi citra kota yang bersangkutan ke skala nasional atau global demi mengembalikan iklim investasi setelah dianggap sebagai "kota pesakitan" akibat krisis ekonomi.

Pengembangan kota kreatif di Indonesia bisa dinilai dari adanya ekosistem kreatif dimana para pelaku industri kreatif, merujuk pada Howkins (2001), diklasifikasikan dalam 16 subsektor: periklanan, arsitektur, seni, kerajinan, desain, fashion, film, musik, seni pertunjukan, penerbitan, penelitian dan pengembangan, perangkat lunak, mainan dan permainan, televisi dan radio, dan permainan video. Pengembangan kota kreatif diimplementasikan melalui pengembangan taman-taman budaya yang diarahkan ke 13 provinsi yaitu Nangroe Aceh Darussalam, Jambi, Sumatera Barat, Jawa Barat, Jawa Tengah, Daerah Istimewa Yogyakarta, Jawa Timur, Kalimantan Barat, Sulawesi Utara, Sulawesi Selatan, Nusa Tenggara Barat, Nusa Tenggara Timur, Papua (2014).

Hasilnya, sejak tahun 2014, setidaknya ada empat kota kreatif yang ditetapkan UNESCO, yaitu Bandung dan Solo, sebagai kota desain; dan Pekalongan dan Yogyakarta sebagai kota kerajinan dan budaya. Sisanya, yang masih dirintis Denpasar, Malang, Bukitinggi Singkawang, Sawahlunto, dan Palembang. Kota kreatif dalam dokumen Bekraf (2014) elemen utamanya adalah keterlibatan industri kreatif, yang berwujud ekspresi tradisional seni rupa, pertunjukan, pertunjukan musik, kriya; hingga industri kreatif modern seperti programer, dan iklan. Sebagai industri, konsumen menjadi orientasi utama proses kreatif. Wawancara kami dengan seorang pegawai bagian keuangan di Bekraf, menunjukkan bahwa selain keuntungan finansial, karya pekerja kreatif diharapkan juga dapat dinikmati masyarakat umum.

"Kami ingin agar UKM atau para pengusaha kuliner tersebut naik kelas, maksudnya adalah memahami proses keuangan yang baik, seperti perencanaan bisnis mengenalkannya pada akses perbankan, pembukuan yang rinci, serta transparansi keuangan, sehingga mudah bagi bank untuk memberikan bantuan usaha mereka supaya lebih berkembang lagi usahanya, mulai dari modal atau perluasan pasar. Jadi kegiatan ekonominya tidak konvensional yang mana hasil karyanya cenderung dinikmati oleh kalangan mereka saja. Sementara, jika sudah memasuki industri kreatif maka ada harapannya masyarakat luas akan menikmati hasil karya mereka pula"

Bagi beberapa kota di Indonesia, kota kreatif diyakini bisa merekrut beberapa pegiat seni dan budaya dalam kategori angkatan kerja, menyerap bonus demografi, terutama sejak berkembangnya start-up yang berbasis transportasi dan e-commerce mulai dari Go-jek, Tokopedia, Bukalapak yang turut menyediakan lapangan kerja serta memberdayakan Usaha Kecil dan Menengah.

Untuk meningkatkan sense of belonging pada kota, pemerintah mengupayakan rebranding citra sebuah kota, salah satunya dengan mengadakan sayembara pembuatan branding kota. Contoh branding kota seperti Jogja Never Ending Asia, Solo The Spirit of Java, Denpasar: Heart of Bali, Stunning Bandung dipandang yang selaras dengan pertumbuhannya sebagai kota kreatif yang berorientasi global. Keinginan 
untuk mengglobal ditunjukkan dengan penggunaan bahasa Inggris tetapi komoditas yang ditawarkan tetap berbasis tradisi.

Pada proses regenerasi urban berikutnya, kami melihat kecenderungan kota untuk membuat creative hubs yang sebagai tempat virtual atau fisikal yang akan menarik para orang yang bekerja atau terlibat dalam industri budaya dan kreatif. Hasil studi yang dilakukan oleh Sudradjat dan Siregar (2017) menunjukkan bahwa ruang ini diinisiasi dan dijalankan oleh individu atau kolektif serta ditujukan untuk menjual barangbarang kesenian. Ada tiga bentuk ruang kreatif di Indonesia menurut mereka: creative hubs, coworking space dan marker spaces yang sama-sama menjadi tempat networking, berkumpul, dan workshop. Creative hubs dalam studi ini banyak berada di kota besar seperti Jakarta, Makassar dan Bandung. Creative hubs bertumbuh seiring dengan berkembangnya industri kreatif dalam kota. Trend ini juga didukung oleh berkembangnya kelas menengah dan para anak muda.

\section{Memperkenalkan Kota Kreatif di Balikpapan}

Istilah kreatif mulai bergulir ke Kota Balikpapan sejak zaman kepemimpinan Walikota Rizal Effendi. Pada satu kesempatan dalam pembukaan seminar ekonomi kreatif bertajuk Developer Day di Balikpapan, apa yang disebut kreatif adalah melek teknologi, anak muda masa kini. Kami kutipkan salah satu pidatonya di bulan Maret 2018,

“...Startup digital ini ekonomi baru, perdagangan dan perekonomian diwarnai internet, dibutuhkan anak-anak kreatif, anak-anak startup. Suka tidak suka, teknologi ini harus diterima...Yang menerima ekonomi ini pasti generasi muda. Kami harap Balikpapan untuk menjadi pelopor ekonomi digital di Kalimantan. Orang yang bisa survive di dunia yang (serba) cepat ini adalah orang yang kreatif dan inovatif"

Walikota Balikpapan sebagaimana para peserta seminar mengartikan wujud nyata dari ekonomi kreatif adalah kehadiran aplikasi Gojek sebagai penanda era disrupsi yang tidak bisa dihindari lagi. Bermacam-macam ide muncul dan tertuang dalam dokumen Laporan Kepala Litbang Bappeda yang disampaikan Musrenbang Kota Balikpapan 2018 terinspirasi dari sukses Gojek berupa pengembangan: Go Green, Go Art, Go Pesona Wisata, Go Halal, Go Smart City, dan Go Batik. Sejauh ini, ide tersebut dianggap masih sesuai dengan slogan Madinatul Iman dengan tujuan mencapai kestabilan masyarakat yang nantinya akan mendorong daya usaha dan inisiatif individu di segala bidang penyelenggaraan pemerintahan dan menjadikan tatanan masyarakat yang beriman, sejahtera, religius, dan berperadaban maju.

Dokumen perencanaan pembangunan daerah Pemerintah Kota Balikpapan 2016-2021, mengamplifikasi mantra Florida (2003) tentang kota kreatif dengan komponen utama kebahagiaan para warga. Konsep kota ini secara eksplisit temaktub dalam dokumen RPJMD sebagai liveable city, turunan dari konsep sustainable city. Pemerintah Kota Balikpapan mendorong 'ekonomi kerakyatan kreatif' yang bertujuan 1) mewujudkan pertumbuhan ekonomi yang akseleratif dan kokoh berbasis pada ekonomi kerakyatan 
yang berwawasan lingkungan (green economy) dan berkeadilan, 2) pengembangan potensi sektor unggulan daerah berfokus pada industri pengolahan yang mengolah bahan mentah sumber daya alam menjadi produk turunan sehingga memberikan nilai tambah tinggi, perdagangan dan jasa, serta pariwisata, 3) Peningkatan daya saing perekonomian Kota Balikpapan tetap memperhatikan kearifan lokal disertai semakin besarnya peranan usaha mikro, kecil, menengah dan koperasi, dan partisipasi aktif segenap pemangku kepentingan dalam pengelolaan aktivitas ekonomi yang tetap memperhatikan kelestarian lingkungan hidup. Secara konseptual, tujuan tersebut tercermin dalam Bagan 1. Berikut ini.

Bagan 1. Strategi Perekonomian Kota Balikpapan

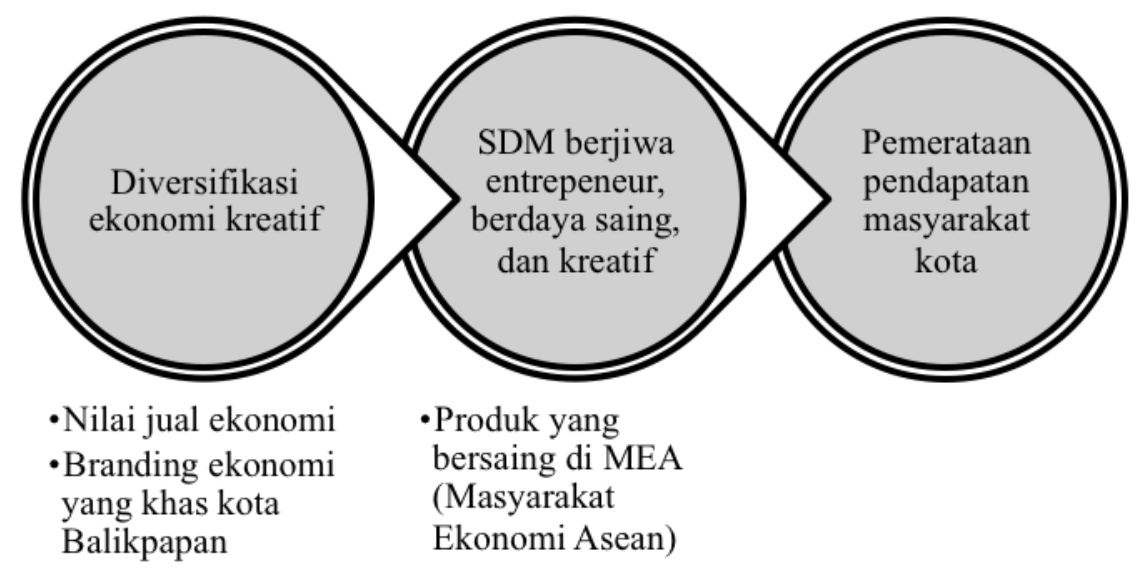

Sumber: Diolah dari Peraturan Walikota No.12 tahun 2017 tentang RKPD Kota Balikpapan 2018.

Setelah melewati uji petik dari Badan Ekonomi Kreatif, maka tahun 2019 berdasarkan Surat Keputusan Kepala Badan Ekonomi Kreatif Republik Indonesia Nomor 83 tahun 2019 tentang Kabupaten/Kota Kreatif, Kota Balikpapan ditahbishkan sebagai Kota Kreatif dengan subsektor unggulan Aplikasi dan Pengembangan Permainan serta Inovasi Berkelanjutan. Dari provinsi Kalimantan Timur diwakili oleh Kota Balikpapan dan Kabupaten Kutai Kertanegara yang diunggulkan seni pertunjukannya. Dua daerah ini bersanding dengan sembilan kota lainnya mulai dari Denpasar, Majalengka, Malang, Kabupaten Gianyar, Semarang, Surakarta, Palembang dan Rembang. Sampai tahun 2019, ada 10 kabupaten. Tabel berikut adalah daftar kota kreatif di Indonesia sampai tahun 2019 yang ditetapkan melalui surat keputusan Kepala Badan Ekonomi Kreatif Republik Indonesia Nomor 83 tahun 2019. 
Tabel 3 Kota Kreatif di Indonesia

\begin{tabular}{llll}
\hline No & Kabupaten/Kota & Subsektor Unggulan & \multicolumn{1}{c}{ Status } \\
\hline 1 & $\begin{array}{l}\text { Kabupaten } \\
\text { Majalengka }\end{array}$ & Seni Pertunjukan & $\begin{array}{l}\text { Ekosistem ekonomi kreatif terbaik } \\
\text { untuk Kabupaten di Pulau Jawa }\end{array}$ \\
\hline 2 & Kota Malang & $\begin{array}{l}\text { Aplikasi dan } \\
\text { Pengembang } \\
\text { Permainan }\end{array}$ & $\begin{array}{l}\text { Ekosistem ekonomi kreatif terbaik } \\
\text { untuk Kota di Pulau Jawa }\end{array}$ \\
\hline 3 & $\begin{array}{l}\text { Kabupaten Kutai } \\
\text { Kartanegara }\end{array}$ & Seni Pertunjukan & $\begin{array}{l}\text { Ekosistem ekonomi kreatif terbaik } \\
\text { untuk Kabupaten di luar Pulau } \\
\text { Jawa }\end{array}$ \\
\hline 4 & Kota Palembang & Kuliner & $\begin{array}{l}\text { Ekosistem ekonomi kreatif terbaik } \\
\text { untuk Kota diluar Pulau Jawa }\end{array}$ \\
\hline 5 & Kabupaten Rembang & Kriya & Konservasi Budaya \\
\hline 6 & Kota Surakarta & Seni Pertunjukan & $\begin{array}{l}\text { Pengembangan ekosistem } \\
\text { (ecosystem development) }\end{array}$ \\
\hline 7 & Kota Semarang & Fesyen & $\begin{array}{l}\text { Pengembangan Bisnis (business } \\
\text { development) }\end{array}$ \\
\hline 8 & Kabupaten Gianyar & Seni Pertunjukan & Daya Tarik Global \\
\hline 9 & Kota Denpasar & Fesyen & $\begin{array}{l}\text { Inovasi Tata Kelola Pemerintahan } \\
\text { (Governance Innovation) }\end{array}$ \\
\hline 10 & Kota Balikpapan & $\begin{array}{l}\text { Aplikasi dan } \\
\text { Pengembang } \\
\end{array}$ & $\begin{array}{l}\text { Inovasi Berkelanjutan (Sustainable } \\
\text { Innovation) }\end{array}$ \\
\hline Punainan & \\
\hline
\end{tabular}

Sumber: Kotakreatif.id

Kami melihat bahwa konsep industri kreatif di Balikpapan sangat cair sehingga menyebabkan kelompok pekerja kreatif bukan lagi pada persoalan skill immaterial (Lazzarato, 1996) atau knowledge labour (Drucker, 1994) tetapi siapa saja yang bergerak dalam bidang kebudayaan, teknologi informasi, berusia muda dan asalkan menjalani fitur ekonomi yang berbeda dengan sumber daya alam atau jam kerja yang berbeda dengan pekerja kantoran. Menjadi menarik ketika sektor ini digerakkan negara melalui birokrasi. Keterlibatan DEKRANASDA (Dewan Kerajinan Nasional Daerah) dan UKM di sektor kriya menjadi hal yang ambigu. Di satu sisi kedua lembaga tersebut berisi para birokrat daerah dan istri pejabat yang dianggap konservatif; namun di sisi lain mereka mengajak dan mendorong kolaborasi dengan pekerja kreatif usia muda.

Di Balikpapan, istilah ekonomi kreatif lebih disukai dibanding industri kreatif, sangat mirip dengan proses kedatangan ekonomi kreatif di negara Post-Sosialis, seperti Rusia dan Estonia (Mäe, 2017; O'Connor, 2005). Dalam satu kasus yang kami amati di lapangan, penyelenggara HUT Kota menganggap kata 'industri' identik dengan kakunya dinding pabrik atau industri ekstraktif yang menghancurkan lingkungan dan mengeruk sumber daya alam serta produksi massal yang dinilai tidak menghargai kreatifitas serta otonomi mereka.

Kebanyakan para pekerja kreatif yang kami wawancarai adalah alumni institut seni dan pendidikan komunikasi di Pulau Jawa yang dibentuk sebagai pekerja kreatif oleh perusahaan multinasional di bidang perminyakan atau pertambangan. Mas Karsa, Mas Riki dan Bang Daniel mendapatkan pengetahuan ekonomi kreatif semasa kuliah di 
Yogyakarta. Dari perusahaan multinasional, mereka mengerti bagaimana menghargai hasil karya kreatif dan menjadi pribadi profesional. Hanya ada dua SMK Multimedia di Balikpapan dan satu institut ilmu komputer yang lebih fokus pada perangkat elektronik informasi. Pun, posisi Kota Balikpapan bukan sebagaimana Kota Jakarta, Bandung, dan Yogyakarta yang sudah siap menuju Kota Kreatif dan memiliki reputasi sebagai kota administratif atau ibukota provinsi. Balikpapan adalah kota berbasis industri ekstraktif yang mana infrastruktur perkotaan dan arah pengembangan sumber daya manusia ditujukan untuk menopang lalu lintas pengolahan sumber daya alam yang berada di Pulau Kalimantan. Narasi ekonomi kreatif banyak berhimpitan dengan kejayaan masa lampau tentang kota tambang dan minyak serta kelas pekerja tradisional.

Tidak seperti Kota Bandung, Yogyakarta, dan Pekalongan yang infrastruktur industri budayanya lebih mapan dan memiliki reputasi sebagai kota seniman, kota pelajar dan kota budaya, Balikpapan bagi sebagian orang adalah kota tambang. Oleh karena itu dilema yang muncul adalah apakah mau mengapropriasi budaya Dayak yang sudah tersebar lewat sejumlah ikon landmark perkotaan dan pusat souvenir? Atau kembali menjual branding 'Kota Minyak' yang sudah melekat dalam narasi sejarah perkotaan, dan mengaktivasi kegiatan wisata alam?

Kami menemui Bang Sandi, kelahiran Balikpapan 32 tahun lalu, yang berprofesi dosen manajemen pemasaran di sebuah kampus lokal. Ia sedang sibuk menata acara untuk hari ulang tahun Balikpapan yang ke-126. Acara ini mengambil tajuk 'Mathilda Fest' yang merujuk pada 'Sumur Mathilda' salah satu ladang minyak legendaris di Balikpapan yang ditemukan 1897. Di acara tersebut, ia tidak mau menggunakan istilah 'pekerja kreatif' namun lebih memilih 'juru karya' atau 'seniman'. Kosakata ini menurutnya lebih halus dibanding 'pekerja' yang terkesan kasar dan menyamakan mereka seperti buruh industri berat. Ia mengartikan 'juru karya' sebagai orang-orang yang independen dan memiliki produk kreatif, berbeda dengan pekerja yang terikat dengan majikan mereka dan masih menggunakan kemampuan fisik: Bang Sandi sepakat dengan mereka yang mengklaim ekonomi kreatif akan menempatkan warga kota sebagai subjek yang aktif serta berorientasi pada kearifan lokal sekaligus mentransformasi pemerintah dari controlling ke empowering. Bang Sandi lebih melihat ekonomi kreatif sebagai 'gerakan' daripada pemahaman ekonomi secara konvesional, sebab memprioritaskan pemecahan persoalan masyarakat layaknya sebuah gerakan sosial. Bang Sandi tidak setuju dengan pendapat kami yang menyamakan Balikpapan dengan Baltimore dan Detroit di Amerika Serikat saat momen deindustrialisasi sebagai penanda dari transisi ke ekonomi kreatif.

Bang Sandi menginisiasi lembaga Forum Ekonomi Kreatif karena melihat tidak ada wadah kreativitas anak muda di Balikpapan, padahal wacana ekonomi kreatif sudah bergulir sejak 2014. Memang benar sudah ada Dekranasda, namun seni dan kerajinan hanyalah satu subsektor dari industri kreatif. Ia menggalang dukungan dari beberapa komunitas dan birokrat daerah, seperti Dinas Perindustrian, Perdagangan dan Koperasi, Dinas Pariwisata, dan Bappeda. Terinspirasi Kota Bandung, ia menyamakan struktur keorganisasian Forum Ekonomi Kreatif mirip dengan Badan Ekonomi Kreatif 
Pusat supaya mudah mengkoordinasikan bantuan. Forum ditempatkan di bawah Bappeda (Badan Perencanaan Pembangunan Daerah) yang paling mengerti arah pembangunan daerah. Para anggotanya adalah para aktivis seni, LSM, dan perwakilan komunitas hobi dan kreatif.

Forum Ekonomi Kreatif berjejaring dalam Indonesia Creative City Network sehingga Bang Sandi akrab dengan jejaring Bandung dan Malang, dua kota yang aparatur kotanya terbuka untuk konsultasi kelembagaan atau program. Dibanding dengan Bandung dan Yogyakarta yang memiliki sekolah seni, broadcasting, teknologi informasi, dan desain komunikasi visual, Balikpapan lebih banyak mengandalkan anak SMA/SMK. Menurut Bang Sandi akhir-akhir ini para pelajar tertarik masuk ke dunia sinema berkat keterlibatan Mas Karsa dan Bang Riki. Sangat kontras dengan keinginan Isteri Walikota, sebagai Ketua Dekranasda, yang menganggap Batik Balikpapan yang sudah teruji dan jelas kontribusinya bagi daerah dibandingkan sektor lainnya.

"Sektor seperti seni pertunjukan, film, dan aplikasi akan potensial sebab Kota Balikpapan memiliki banyak komunitas dan perkumpulan kedaerahan yang berasal dari para perantau seperti Ponorogo yang sering menampilkan seni Reyog saat ulang tahun kota atau pertunjukan di lapangan (ruang publik), mereka bisa untuk difilmkan dan diperkenalkan kepada khalayak ramai bahwa kota ini (Balikpapan) sangat beragam budayanya. Sementara, anak muda saat ini juga lebih suka menjadi Youtuber atau vlogger yang mana bisa kompatibel dengan perfilman, sisanya (anak muda) bisa terserap pula ke bidang aplikasi, kan mereka generasi internet jadi lebih paham lah dunia teknologi informasi"

Pengembangan sektor kreatif mestinya dipilih berdasarkan alur yang sehat mulai dari hulu hingga ke hilir industri (Prince, 2010, 2014). Pengembangan kota kreatif di suatu negara tidak harus mengikuti trend global atau kesuksesan daerah lain (Bunnell, 2015; González, 2006). Pada kasus Balikpapan, kami melihat bahwa pengembangan kota kreatif oleh negara melalui aparat dan lembaga bentukan negara dengan keinginan para pelaku. Pada masa otonomi daerah dan desentralisasi, peluang daerah untuk mengajukan usulan pengembangan wilayah dan saling referensi dalam perencanaan kota juga amat memungkinkan, sehingga nampaknya itulah yang mendorong para pelaku industri kreatif lebih percaya diri (Bunnell et al., 2013; Söderström, 2014).

\section{Kesimpulan}

Alih-alih menekankan kajian kebijakan pada problem efisiensi, implementasi atau evaluasi, antropologi lebih mempersoalkan proses transfer kebijakan, peralihan pengetahuan, mutasi dan hibridisasi, kontestasi, negosiasi, atau siasat dari siapapun yang terlibat dalam kebijakan ini entah ia yang menjadi perumus kebijakan atau target kebijakan. Sebagai sebuah instrumen praktik kekuasaan, kebijakan publik tidak berwatak monolit, atau absolut namun diwarnai saling silang kepentingan.

Melalui kasus Balikpapan, kami berpendapat bahwa sebuah kebijakan akan menghasilkan imajinari geografis berupa kisah sukses yang membentuk pengetahuan 
dari sebuah kebijakan tertentu yang sudah berlangsung pada satu wilayah untuk kemudian dilegitimasi dan dipraktikkan oleh aktor pembuat kebijakan lainnya.

Pada konteks Kota Balikpapan, ekonomi berbasis ekstraksi sumber daya alam mengalami restriksi dan tekanan dari berbagai lembaga internasional akibat ketidakberlanjutan. Ketika industri besar berbasis ekstraksi terhambat, ekonomi kota lesu. Studi kami menunjukkan bahwa kebijakan kota kreatif beroperasi melalui banyak saluran kepentingan antar kelompok yang menginginkan alternatif ekonomi baru bagi perkotaan dalam kerangka kelestarian lingkungan alam, sosial, dan ekonomi.

\section{Ucapan terimakasih}

Terimakasih pada Dave Lumenta, Inaya Rakhmani, dan Irwan Hidayana dari Universitas Indonesia yang telah memberi komentar dan gagasan. Ucapan serupa juga kami tujukan kepada para informan kami pekerja kreatif di Balikpapan, pejabat Pemerintah Kota Balikpapan, dan aparat di Badan Ekonomi Kreatif di Jakarta.

\section{Conflicts of interest}

Penulis menyatakan tidak ada konflik kepentingan.

\section{Referensi}

Aritenang, A. (2015). Transfer Policy on Creative City: The Case of Bandung, Indonesia. Procedia - Social and Behavioral Sciences. https://doi.org/10.1016/j.sbspro.2015.05.051

Baker, T., Cook, I. R., McCann, E., Temenos, C., \& Ward, K. (2016). Policies on the move: The transatlantic travels of tax increment financing. Annals of the American Association of Geographers. https:// doi.org/10.1080/00045608.2015.1113111

BAPPEDA Kota Balikpapan. RPJMD (Rencana Pembangunan Jangka Menengah Daerah), 2016-2021

BAPPEDA Kota Denpasar. 2010. Membangun Denpasar melalui City Branding.

Brenner, N., Peck, J., \& Theodore, N. (2010). Variegated neoliberalization: Geographies, modalities, pathways. Global Networks. https://doi.org/10.1111/j.14710374.2009.00277.x

Bunnell, T. (2015). Antecedent Cities and Inter-referencing Effects: Learning from and Extending Beyond Critiques of Neoliberalisation. Urban Studies. https://doi.org/10.1177/0042098013505882

Bunnell, T., Miller, M. A., Phelps, N. A., \& Taylor, J. (2013). Urban Development in a Decentralized Indonesia: Two Success Stories?* Tim Bunnell, Michelle Ann Miller, Nicholas A. Phelps and John Taylor Forthcoming in. Pacific Affairs.

Council, B. (2010). Mapping the creative industries: a toolkit. Erişim Https://Creativeconomy.

Britishcouncil.

Org/Media/Uploads/Files/English_mapping_the_creative_industries_a_toolkit_2-2. Pdf.

Cunningham, S. (2012). The creative cities discourse: Production and/or consumption? In Cities, Cultural Policy and Governance. https:// doi.org/10.4135/9781446254523.n8

Drucker, P. F. (1994). Post-capitalist society. Routledge.

Faist, T. (2013). The mobility turn: A new paradigm for the social sciences? In Ethnic and Racial Studies. https:/ / doi.org/10.1080/01419870.2013.812229

Florida, R. (2003). Cities and the Creative Class. City and Community. 
https:// doi.org/10.1111/1540-6040.00034

González, S. (2006). Scalar narratives in Bilbao: A cultural politics of scales approach to the study of urban policy. International Journal of Urban and Regional Research. https://doi.org/10.1111/j.1468-2427.2006.00693.x

Healy, K. (2002). What's new for culture in the new economy? Journal of Arts Management Law and Society. https:/ / doi.org/10.1080/10632920209596967

Howkins, J. (2001). The Creative Economy: How People Make Money from Ideas. Allen Lane.

Jonas, A. E. G., McCann, E., \& Thomas, M. (2015). Urban geography: a critical introduction. John Wiley \& Sons.

Jones, T. (2015). Kebudayaan dan kekuasaan di Indonesia: Kebijakan budaya selama abad ke 20 hingga Era Reformasi. Yayasan Pustaka Obor Indonesia.

Landry, C. (2000). The Creative City. Toolkits for urban innovators. London.

Laporan Kepala Bappeda Litbang dalam Musrenbang (Musyawarah Perencanaan Pembangunan), Kota Balikpapan, 21 Maret 2018

Lange, B. (2015). Cultural industries in transition economies. The Routledge Companion to the Cultural Industries, 273-283.

Lazzarato, M. (1996). Immaterial labour. Contemporary Marxist Theory, 77.

Li, T. M. (2007). The will to improve: Governmentality, development, and the practice of politics. duke university Press.

Li, T. M. (2014). Land's end: capitalist relations on an indigenous frontier. Duke University Press.

Lowe, C. (2003). The magic of place; Sama at sea and on land in Sulawesi, Indonesia. Bijdragen Tot de Taal-, Land-En Volkenkunde/Journal of the Humanities and Social Sciences of Southeast Asia, 159(1), 109-133.

Mäe, R. (2017). The story of e-Estonia: a discourse-theoretical approach. Baltic Worlds.

Mccann, E. (2011). Urban policy mobilities and global circuits of knowledge: Toward a research agenda. Annals of the Association of American Geographers. https://doi.org/10.1080/00045608.2010.520219

McCann, E., \& Ward, K. (2012). Assembling urbanism: Following policies and "studying through" the sites and situations of policy making. Environment and Planning A. https:/ / doi.org/10.1068/a44178

O'Connor, J. (2005). Creative exports: Taking cultural industries to St Petersburg. International Journal of Cultural Policy. https:// doi.org/10.1080/10286630500067747

O'Connor, J., \& Gu, X. (2015). Creative clusters in Shanghai: Transnational intermediaries and the creative economy. In Making Cultural Cities in Asia: Mobility, Assemblage, and the Politics of Aspirational Urbanism. https:// doi.org/10.4324/9781315726052

Ong, A. (2007). Neoliberalism as a mobile technology. Transactions of the Institute of British Geographers. https:// doi.org/10.1111/j.1475-5661.2007.00234.x

Pariwisata, K. (2014). Ekonomi Kreatif: Rencana Aksi Jangka Menengah 2015-2019. Jakarta, Kementrian Pariwisata Dan Ekonomi Kreatif.

Peck, J. (2011). Geographies of policy: From transfer-diffusion to mobility-mutation. Progress in Human Geography. https:/ / doi.org/10.1177/0309132510394010

Peck, J., \& Theodore, N. (2010). Mobilizing policy: Models, methods, and mutations. Geoforum, 41(2), 169-174. https:/ / doi.org/10.1016/j.geoforum.2010.01.002

Peraturan Walikota No.12 tahun 2017 tentang RKPD (Rencana Kerja Pembangunan Daerah) Kota Balikpapan 2018

Prince, R. (2010). Policy transfer as policy assemblage: Making policy for the creative 
industries in New Zealand. Environment and Planning $A$. https://doi.org/10.1068/a4224

Prince, R. (2014). Consultants and the global assemblage of culture and creativity. Transactions of the Institute of British Geographers. https://doi.org/10.1111/tran.12012

Robinson, K. M. (1986). Stepchildren of progress: The political economy of development in an Indonesian mining town. Suny Press.

Rossi, U. (2017). Cities in global capitalism. John Wiley \& Sons.

Roy, A., \& Ong, A. (2011). Worlding Cities: Asian Experiments and the Art of being Global. In Worlding Cities: Asian Experiments and the Art of being Global. https://doi.org/10.1002/9781444346800

Scott, A. J. (2014). Beyond the Creative City: Cognitive-Cultural Capitalism and the New Urbanism. Regional Studies. https://doi.org/10.1080/00343404.2014.891010

Sheller, M., \& Urry, J. (2006). The new mobilities paradigm. Environment and Planning A. https://doi.org/10.1068/a37268

Shore, C., \& Wright, S. (2003). Anthropology of policy: Perspectives on governance and power. Routledge.

Shore, C., Wright, S., \& Pero, D. (2011). Policy Worlds: Anthropology and the analysis of contemporary power. In Policy Worlds: Anthropology and the Analysis of Contemporary Power.

Siregar, F., \& Sudrajat, D. (2017). Enabling Spaces: Mapping creative hubs in Indonesia. Jakarta: Centre for Innovation Policy and Governance Indonesia Sustainability Centre.

Söderström, O. (2014). Cities in Relations: Trajectories of Urban Development in Hanoi and Ouagadougou. In Cities in Relations: Trajectories of Urban Development in Hanoi and Ouagadougou. https:// doi.org/10.1002/9781118632758

Temenos, C., \& Mccann, E. (2013). Geographies of Policy Mobilities. Geography Compass. https://doi.org/10.1111/gec3.12063

Tsing, A. L. (1993). In the Realm of the Diamond Queen. In Princeton University Press.

Urry, J. (2000). Sociology beyond Societies mobilities for XXI Century. In Routledge London .

Unesco Creative City Network. Mission statement https://en.unesco.org/creativecities/sites/creative-cities/files/uccn_mission_statement_rev_nov_2017.pdf

van den Berg, M. (2012). Femininity As a City Marketing Strategy: Gender Bending $\begin{array}{llll}\text { Rotterdam. Urban } & \text { Studies, }\end{array}$ https://doi.org/10.1177/0042098010396240 